\title{
Cox-Gompertz model for analysis of the time of stay in an Anglo-Nubian goat herd
}

\section{Modelo de Cox-Gompertz para análise do tempo de permanência em um rebanho de cabras da raça Anglonubiana}

\author{
Cleide Mayra Menezes Lima ${ }^{1 *}$; Vera Lucia Damasceno Tomazella2; \\ Severino Cavalcante de Sousa Junior3; José Elivalto Guimarães Campelo4; \\ Luciano Silva Sena5; Waldomiro Barioni Junior ${ }^{6}$
}

\section{Highlights}

Endoparasitism is related to longevity of Anglo-Nubian goats in the herd.

Body condition score, birth weight and birth season are related to longevity.

Cox-Gompertz proportional hazards model allows assessing goat longevity in the herd.

\section{Abstract}

Anglo-Nubian goats are hardy animals able to adapt to tropical environments, where their farming is usually held on pasture. However, climatic conditions in this environment also favor endoparasitism, which implies a negative aspect if sensitivity to worm infections interferes by reducing the reproductive lifespan of females, as their stay in the herd is a trait of great importance for efficient goat farming. In this respect, this study proposes to use the survival analysis methodology with the Cox-Gompertz proportional hazards model to assess the length of stay in the herd by relating the removal of females due to death with worm infection being the main cause to other forms of culling, using information from 101 Anglo-Nubian goats born from 2009 to 2013 in an experimental herd from Teresina - PI, Brazil. The Cox-Gompertz proportional hazards model chose body condition score, birth weight and birth season as important covariates ( $p$-value $\leq 10 \%)$.

1 Graduate Program in Animal Science, Agrarian Sciences Center, CCA, Universidade Federal de Piauí, UFPI, Campus Ministro Petrônio Portella, Teresina, Pl, Brazil. E-mail: cleide.mayra@ufpi.edu.br

2 Profa Dra, Department of Statistics, Universidade Federal de São Carlos, UFSCar, São Carlos, SP, Brazil. E-mail: vera@ufscar.br

${ }^{3}$ Prof. Dr., Department of Animal Science, Universidade Federal de Parnaíba Delta, UFDPA, Campus of Parnaíba, Parnaíba, PI, Brazil. E-mail: sevzoo@ufpi.edu.br

${ }^{4}$ Prof. Dr., Department of Animal Science, CCA, UFPI, Campus Ministro Petrônio Portella, Teresina, Pl, Brazil. E-mail: elivalto@pq.cnpq.br

${ }^{5}$ Ph.D in Animal Science, Graduate Program in Animal Science, CCA, UFPI, Campus Ministro Petrônio Portella, Teresina, PI, Brazil. E-mail: lucianossbj@hotmail.com

${ }^{6}$ Researcher of the Department of Statistical Methods, Empresa Brasileira de Pesquisa Agropecuária, EMBRAPA Pecuária Sudeste, São Carlos, SP, Brazil. E-mail: waldomiro.barioni@gmail.com

* Author for correspondence

Received: Sept. 12, 2020 - Approved: May 31, 2021 
Body condition score showed to be a favorable factor for the longer stay of the goats in the herd. Eggs per gram, age at first kidding, birth type and dam age were not significant. The Cox-Gompertz proportional hazards model is suitable for fitting the statistical model to estimate the length of stay in the herd, with censoring related to endoparasitism in Anglo-Nubian goats.

Key words: Body condition score. Censoring. Culling. EPG. Famacha.

\section{Resumo}

Os caprinos da raça Anglonubiana apresentam-se rústicos com adaptabilidade a ambiente tropical, onde sua exploração ocorre geralmente em pasto. Entretanto, condições climáticas desse ambiente favorecem também o endoparasitismo, implicando num aspecto negativo se a sensibilidade a verminoses interferir reduzindo a duração da vida reprodutiva de fêmeas, pois a permanência delas no rebanho é uma característica de grande importância para a maior eficiência da caprinocultura. Neste contexto, objetiva-se com este estudo utilizar a metodologia de análise de sobrevivência com modelo de riscos proporcionais de Cox-Gompertz para avaliação do tempo permanência no rebanho, relacionando a saída da fêmea por morte tendo a verminose como a principal causa, em relação a outras formas de descarte, utilizandose informações de 101 cabras da raça Anglonubiana nascidas no período de 2009 a 2013 em reba nho experimental localizado em Teresina-Piauí. O modelo de riscos proporcionais de Cox-Gompertz, elegeu como covariáveis importantes ( $p$-valor $\leq 10 \%$ ): o escore da condição corporal (ECC), o peso ao nascer (PN) e a estação de nascimento (EN). O ECC se apresentou como fator favorável a maior permanência das cabras no rebanho. Não foram significativos o OPG, idade ao primeiro parto, tipo de nascimento e idade da mãe. O modelo de riscos proporcionais de Cox-Gompertz se mostra adequado no ajuste do modelo estatístico para estimar o tempo de permanência no rebanho, com censura relacionada a endoparasitismo em cabras da raça Anglonubiana.

Palavras-chave: Censura. Descarte. Escore de condição corporal. Famacha. OPG.

\section{Introduction}

Small-ruminant husbandry is a widespread activity across the globe. Goat farming is considered to have gzzzreat social and economic potential, especially in the northeast region of Brazil (Conrado, Arandas, \& Ribeiro, 2015), where it is often practiced in inhospitable places, due to environmental factors and nutritional limitations that affect animal performance and longevity.

The negative consequences of exposure to endoparasitism are not a recent problem (Bishop, 2012; Molento et al., 2013). Indeed, this is still a prominent subject in Brazil, in several areas of knowledge (Torres, 2019), due to its importance in animal production systems and the higher sensitivity of the offspring during the stress of weaning and of adult animals at times of increased nutrient requirements, such as the end of pregnancy and lactation (Silveira et al., 2013). The animals' resistance to worm infections, in turn, is an alternative that has been mentioned in the literature for coexistence with or as a way to combat parasitism (Molento et al., 2013).

Diseases cause impacts on livestock production, due either to the cost of treatment and prevention or production losses related to the farming system (Stotzer et al., 2014). 
For this reason, it is very important to know the action of parasitism on the goat. Because dams stay longer in the herd, their health costs are higher than those of other animal categories. Therefore, this is an important component of the maintenance cost that should be minimized so that dams can become efficient in economic terms.

Economic efficiency in this activity entails maintaining the best-performing animals in the herd as long as possible. Thus, factors that act in favor or against the animal remaining productive must be identified so decisions can be made with an economic vision on the culling and replacement of dams. According to Queiroz (2012), fertility is a trait of great importance for the productive lifespan of females, and being strongly influenced by the management and the environment, it indicates the ability of the animal to stay in the herd (stayability). This variable can be determined as the difference between the age at which the animal is culled and the age at first kidding, when it starts to participate effectively as a productive unit in the herd.

Anglo-Nubian goats have been used for production in the northeast of Brazil because of characteristics that set them apart from other goat breeds managed extensively in that region (M. G. C. M. Silva, Diniz, \& Rosado, 2015). However, their infection by gastrointestinal endoparasites is one of the main factors limiting their production, as it compromises their performance in the herd (Quintas \& Cardoso, 2012).

Studies are being developed to investigate the time animals remain productive in a herd, under the premise that by extending the functional life of females, replacement costs will be reduced due to the better use of the animal in the system (Ferreira et al., 2020). Survival analysis is a statistical methodology that has been used to evaluate data on the time until the occurrence of an event of interest (failure time), in the presence of censorship (Colosimo \& Giolo, 2006). In the study of longevity by survival analysis, some peculiarities are important, the main one being the presence of censorship (which warrants the use of this analysis). In addition to this characteristic, the influence of explanatory variables must also be considered. In survival analysis, these variables are called fixed covariates. The combined inclusion of censored and uncensored information in the analyses is one of the main advantages of survival analysis, when compared with other methods of studying longevity. Applying it in goats, Lima et al. (2021) recommended survival analysis for the identification of weaknesses in the animals, which would be useful in breeding programs and in studies of resistance to worm infections.

Survival models can be parametric or semi-parametric. The semi-parametric model is named so because a parametric form is assumed only for the term that holds the effects of the explanatory variables. In this way, the parameters in question are the coefficients of the explanatory variables considered in the model, which are usually those to be estimated. An example of a semiparametric model is the Cox model (Cox, 1972). In the parametric model, however, both the hazard rate and the term that contains the explanatory variables take a parametric form. A parametric survival model is one that assumes that the response variable (survival time) follows a known distribution (Colosimo \& Giolo, 2006). The most used distribution type for modeling survival data is Weibull distribution. The Gompertz model is used to examine death patterns throughout life not only in humans but 
also other organisms (Kirkwood, 2015). Finch and Pike (1996) stated that the Gompertz model offers a good approximation for the age-related mortality rates of adult mammals and birds.

In this respect, this study proposes to undertake a survival analysis through the parametric Cox proportional hazards model, where we assumed a Gompertz distribution for the length of stay of goats at risk, originating the Cox-Gompertz model. This model can assess the length of stay of female goats in the herd, relating their removal due to death, with worm infection as the main cause, to other forms of culling performed in Brazil. Considering several factors, e.g., the advantages of survival analysis, the dearth of studies with this methodology in AngloNubian goats in Brazil, the possibility of using the results to guide longevity assessment strategies and the economic importance of longevity, it is understood that this study could directly benefit the producer in the search for more long-lived and helminth-resistant animals.

\section{Material and Methods}

This study was approved by the Ethics Committee of the Federal University of Piauí (UFPI) and developed based on the rules established by the Animal Ethics and Experimentation Committee of this Higher Education Institution (registration no. 550/19).

\section{Material}

The information used in the study was edited from the database of the experimental herd belonging to the Center for Agricultural
Sciences at UFPI, located in Teresina - PI, Brazil, located at the following geographical coordinates: $5^{\circ} 5^{\prime} 20^{\prime \prime} \mathrm{S}$ and $42^{\circ} 48^{\prime} 07 \mathrm{~W}$. In editing, the period from 2009 to 2019 was considered, using only goats with complete information regarding egg count per gram of feces (EPG), degree of anemia as indicated by the Famacha score (FAMACHA), body condition score (BCS), birth weight (BW), birth date and birth type (BT), totaling 101 goats born between 2009 and 2013.

The animals were raised in a semiintensive system, where the males were culled at four months of age and the sires were kept confined. During the rainy season of the year, the pregnant goats grazed in the last third of gestation and lactation, whereas in the dry season they were joined with the empty goats and doelings in the paddocks. The animals had access to pasture during the day, in an area formed by native vegetation intercropped with cultivated grasses, mainly gamba grass (Andropogon gayanus) and guinea grass (Panicum maximum). Bermudagrass (Cynodon spp.) was used in the form of hay and elephant grass (Pennisetum purpureum Schum) was given as a roughage source after the animals returned to the fold in the early afternoon, in the dry season of the year.

In health management, the vermifuge active principle was rotated based on an anthelmintic resistance test. The criterion for the animal to be dewormed was EPG. Application in all females at reproductive age occurred when $10 \%$ of the animals in the herd had an EPG count $\geq 1,000$, as suggested by Costa, Simões and Riet-Correa (2011). To counterbalance the effects of immunosuppression, which favors parasitism in the peripartum period, all goats were also dewormed in the week after kidding as a 
measure of protection of the potentially more sensitive animals, which were incorporated intentionally for four generations to increase variability of resistance to worm infections in the herd.

In reproductive management, one breeding season (mating) was adopted in each semester of the year, and females were replaced with animals from the very herd, also incorporating the high-EPG doelings to increase the resistance response to worm infection. The EPG, BCS and FAMACHA data were collected on average every 40 days. In editing, only the collections that took place during the gestation-lactation period of the goats were considered, all of which were measured on the same date.

Body condition score was obtained by assigning scores from 1 (emaciated) to 5 (obese), considering the average of the values assigned by three different evaluators (Machado, Corrêa, Barbosa, \& Bergamaschi, 2008). The degree of anemia was also assessed by three evaluators, who assigned a score from 1 (pinkish-red) to 5 (pale white) to the hue of the animals' conjunctiva using a guide card developed for use in the field based on the Famacha method (Molento et al., 2004).

To model the length of stay (in months) after the beginning of the goats' reproductive life until the occurrence of failure (death, with the prevalence of presence of clinical signs associated with worm infection), relative to the removal of the herd due to death or other cause, time was considered a response variable and expressed on a continuous scale and the age at first kidding was considered the start of the study.
Variable $T$ (time) was determined as the difference between the date of first kidding and the culling date. The date of the last culling in the herd was considered the final observation period for animals that had not yet been culled (06/03/2019). The failure indicator $(\delta=1)$ was defined as death by worm infection (event of interest), whereas censoring $(\delta=0)$ was defined for animals that were culled for other reasons (slaughter, research, kidding and others) or remained alive in the herd. The random right censoring type was adopted.

The covariates considered as possible hazard factors for the length of stay of AngloNubian goats in the herd, after the first kidding, were BS - birth season (0 - rainy, 1 - dry); BT - birth type (0 - single, 1 - multiple); AFK goat age at first kidding (in months); BCS body condition score; EPG - eggs per gram of feces ( $\left.\log _{10} E P G\right) ;$ BW - birth weight (in kg); FAMACHA - degree of anemia as indicated by the Famacha method ( 0 if FAMACHA $<3$ [nonanemic]; and 1 if FAMACHA $\geq 3$ [anemic]); and DAK - dam age at kidding (in months).

\section{Methods}

To determine the time the goats stayed in the herd after the first kidding, survival analysis techniques were used. Due to the presence of censoring in survival data, they are summarized with estimates of the survival function and the hazard function (Moore, 2016). To estimate these functions, we applied the non-parametric method of Kaplan and Meier (Kaplan \& Meier, 1958). The Log-rank test, proposed by Mantel and Haenzel (1959), was used to compare survival functions of two or more groups. To analyze the influence of covariates on the time the goats stay in the 
herd, after the first kidding, the Cox-Gompertz proportional hazards model was adopted. All statistical analyses were performed using free statistical software $\mathrm{R}$, version 3.3.1 (R Core Team [R], 2013).

\section{Cox-Gompertz proportional hazards model}

The Cox proportional hazards model (Cox, 1972) allows modeling survival data in the presence of covariates, through the hazard function. According to the Cox model, the hazard function for an animal with a covariate vector " $\mathrm{x}$ " is given by:

$$
h(t \mid \mathbf{x})=h_{0}(t) \exp \left(\boldsymbol{\beta}^{\prime} \mathbf{x}\right) .
$$

where $h_{0}(t)$ is the baseline hazard function, that is, the hazard of an animal with all covariates equal to zero; $\left(\beta_{1}, \beta_{2}, \ldots, \beta_{k}\right)$ is the vector of dimension $\mathrm{k}$ of unknown regression coefficients to be estimated; and $x=\left(x_{1}, x_{2}, \ldots\right.$, $x_{k}$ ) is the vector of dimension $k$ of covariates for animal i.

Model (1) is composed of the product of two components: $\exp \left(\boldsymbol{\beta}^{\prime} \mathbf{x}\right)$, which measures the effect of covariates; and $h_{0}(t)$, which can be parametric or not. In the semiparametric case, the $h_{0}(t)$ component is arbitrary and considered a non-negative function of time; when parametric, it can assume distributions such as Weibull, Log-normal, Gompertz and others.

The main assumption for model (1) is that the failure rate ratio of two different animals is constant over time, i.e., the hazard function ratio for two animals $i$ and $j$ is given by:

$\frac{h\left(t \mid \boldsymbol{x}_{\boldsymbol{i}}\right)}{h\left(t \mid \boldsymbol{x}_{\boldsymbol{j}}\right)}=\frac{h_{0}(t) \exp \left\{\boldsymbol{\beta}^{\prime} \boldsymbol{x}_{\boldsymbol{i}}\right\}}{h_{0}(t) \exp \left\{\boldsymbol{\beta}^{\prime} \boldsymbol{x}_{\boldsymbol{j}}\right\}}=\exp \left\{\boldsymbol{\beta}^{\prime}\left(\boldsymbol{x}_{\boldsymbol{i}}-\boldsymbol{x}_{\boldsymbol{j}}\right)\right\}$.
Coefficients in a Cox regression model are interpreted by the exp $\left(\beta_{i}\right)$ quantities, called hazard or failure rate ratios (FRR). A $\beta_{i}$ value greater than zero, or equivalent to a hazard rate greater than one, indicates that, like the value of $i$-ths covariates, the risk of failure increases and, therefore, the duration of survival decreases. In other words, a hazard rate above 1 indicates a covariate that is positively associated with the probability of the event of interest and, therefore, negatively associated with the duration of survival. In short, FRR=1: no effect; FRR<1: decreased hazard; and FRR>1: increased hazard.

In the Cox model, the survival function is defined by:

$S(t \mid \mathbf{x})=\exp \left\{-\int_{0}^{t} h_{0}(u) \exp \left\{\boldsymbol{\beta}^{\prime} \mathbf{x}\right\} d u\right\}=\left[S_{0}(t)\right]^{\exp \left\{\boldsymbol{\beta}^{\prime} \mathbf{x}\right\} .}$

where $S_{o}(t)$ is the baseline survival function, that is, the survival function of an animal with all covariates equal to zero.

In this study, we consider the parametric approach for the Cox model, where the lifespan of goats at risk follows a Gompertz distribution (Dey, Moala, \& Kumar, 2018). Table 1 shows the probability density $f(t)$, hazard $h_{o}(t)$ and survival $S_{o}(t)$ functions for the Gompertz, Weibull and log-Normal distributions that serve as a comparison for the proposed Cox-Gompertz model.

which is constant over time. 
Table 1

Density $f(t)$, survival $S_{0}(t)$ and hazard $h_{0}(t)$ functions of the Gompertz, Weibull and log-Normal distributions

\begin{tabular}{cccc} 
& Gompertz & Weibull & log-Normal \\
$f(t)$ & $\lambda \exp (\gamma t) \exp \left\{-\left(\frac{\lambda}{\gamma}\right)\left(e^{\gamma t}-1\right)\right\}$ & $\frac{\gamma}{\lambda \gamma} t^{\gamma-1} \exp \left\{-\left(\frac{t}{\lambda}\right)^{\lambda}\right\}$ & $\frac{1}{\sqrt{2 \pi} t \sigma} \exp \left\{-\frac{1}{2}\left(\frac{\log (t)-\mu}{\sigma}\right)^{2}\right\}$ \\
$S_{0}(t)$ & $\exp \left\{-\frac{\lambda}{\gamma}(\exp (\gamma t)-1)\right\}$ & $\exp \left\{-\left(\frac{t}{\lambda}\right)^{\lambda}\right\}$ & $\boldsymbol{\Phi}\left(\frac{-\log (\boldsymbol{t})+\mu}{\sigma}\right)$ \\
$h_{o}(t)$ & $\lambda \exp (\gamma t)$ & $\frac{\gamma}{\lambda^{\gamma}} t^{\gamma-1}$ & $\frac{f(t)}{S_{0}(t)}$ \\
\hline
\end{tabular}

Thus, by replacing the baseline hazard function $h_{0}(t)$ and the baseline survival function $S_{\circ}(t)$ of Gompertz distribution in (1) and (3), respectively, we have the Cox-Gompertz proportional hazards model, whose hazard function is defined as shown below:

$$
h(t \mid \mathbf{x})=\lambda \exp (\gamma t) \exp \left(\boldsymbol{\beta}^{\prime} \mathbf{x}\right),
$$

and the survival function is rewritten as follows:

$$
S(t \mid \mathbf{x})==\left[\exp \left\{-\frac{\lambda}{\gamma}(\exp (\gamma t)-1)\right\}\right]^{\exp \left\{\boldsymbol{\beta}^{\prime} \mathbf{x}\right\}}
$$

\section{Inferences}

In survival analysis, the maximum likelihood method is used to estimate the parameters $\boldsymbol{\theta}=(\gamma, \lambda, \boldsymbol{\beta})$ of the model (4), because this method is able to incorporate censored data.

Consider the $W=(n, \boldsymbol{t}, \boldsymbol{\delta}, \mathbf{X})$ data set, where $\boldsymbol{t}=\left(t_{1}, \ldots, t_{n}\right)$ are the observed failure times; $\boldsymbol{\delta}=\left(\delta_{1}, \ldots, \delta_{n}\right){ }^{\prime}$ are the censored failure times; and $\mathbf{X}$ is an $n \times k$ matrix containing the covariates. Assuming that the data are independent and identically distributed, the likelihood function, with censored data, according to Lawless (2011), is defined by:

$$
L(\boldsymbol{\theta})=\prod_{i=1}^{n}\left[h\left(t_{i} \mid \boldsymbol{x}_{i}\right)\right]^{\delta_{i}} S\left(t_{i} \mid \boldsymbol{x}_{i}\right) .
$$

where $\delta_{i}$ is the censoring indicator. have:

$$
\text { Replacing functions (4) and (5) in (6), we }
$$

$$
\begin{aligned}
& L(\boldsymbol{\theta})=\prod_{i=1}^{n}\left[\lambda \exp (\gamma t) \exp \left\{\boldsymbol{\beta}^{\prime} \boldsymbol{x}_{\boldsymbol{i}}\right\}\right]^{\delta_{i}} \\
& {\left[\exp \left\{-\frac{\lambda}{\gamma}(\exp (\gamma t)-1)\right\}\right]^{\exp \left\{\boldsymbol{\beta}^{\prime} \boldsymbol{x}_{\boldsymbol{i}}\right\}}}
\end{aligned}
$$

Maximum likelihood estimates are obtained by the numerical maximization of the log-likelihood function $(\log [L(\theta)])$. The Optim package of R software and the "BFGS" method were used for maximization.

The asymptotic confidence intervals for the model parameters are based on the asymptotic normality properties of the maximum likelihood estimators. If $\hat{\boldsymbol{\theta}}$ denotes the maximum likelihood estimators of $\boldsymbol{\theta}$, then the distribution of $\hat{\boldsymbol{\theta}}-\boldsymbol{\theta}$ is approximated by a q-variate normal distribution with zero mean and covariance matrix $\mathrm{I}^{-1}(\hat{\theta})$, where $I(\theta)$ is the observed information matrix. Thus, an asymptotic confidence interval with 100 (1$\alpha) \%$ for each parameter $\theta_{i}$ is:

$$
C I(\boldsymbol{\theta},(1-\alpha) 100 \%)=\left(\hat{\theta}_{i}-z_{\alpha / 2} \sqrt{\widehat{V}\left(\theta_{i}\right)}, \widehat{\theta}_{i}+\sqrt{\widehat{V}\left(\theta_{i}\right)}\right)
$$


where $\hat{V}\left(\theta_{i}\right)$ is the element of the main diagonal of $I^{-1}(\hat{\theta})$, corresponding to each parameter; and $z_{\alpha / 2}$ is the quantile $(1-\alpha) \%$ of the standard normal distribution.

To test the hypotheses related to the vector of parameters $\boldsymbol{\theta}$, we used the three tests that are generally recommended, namely, Wald, Score and Likelihood Ratio (Colosimo \& Giolo, 2006). The choice of the model was based on the Akaike information criterion (AIC), proposed by Akaike (1974), and the Bayesian information criterion (BIC), proposed by Schwarz (1978), considering those with the lowest AIC and BIC values.

To assess the adequacy of the CoxGompertz model, we employed methods that are essentially based on: i) Cox-Snell residuals (Cox \& Snell, 1968) and standardized residuals, useful for examining the overall fit of the model ii) Martingale residuals, useful in determining the functional form (linear, quadratic, etc.) of a covariate, which is generally continuous and was included in the regression model; iii) Deviance residuals, which help to examine the accuracy of the model for each individual under study; and iv) Schoenfeld residuals, to analyze the assumption of proportional hazards (Nikulin, Balakrishnan, Mesbah, \& Limnios, 2013).

\section{Results and Discussion}

Longevity is an indirect global trait to quantify the productive-life expectancy of animals. It is desirable that animals that are individually more efficient remain in the herd, since, collectively, they are those which contribute to the sustainability of the livestock activity by ensuring profitability to the farm (Castañeda-Bustos et al., 2017).
The relevance of the present study lies in the fact that health is an important component of the life expectancy of goats, which must remain productive for a long time in the herd, where they are usually exposed to the action of pathological agents such as worms. Coupled with this, the goats' response is usually evaluated based on variations in EPG, BCS and FAMACHA, with a view to clearly showing the expression of resistance or sensitivity in addition to the expression of resilience. The latter consists of the animal even if parasitized being able to maintain good production levels, which was addressed by Bishop (2012) and Hayward et al. (2014) as an indication of tolerance to parasitism.

Considering this approach as a prerogative, from 2001, the management activities in the herd were directed towards adapting it to the study of the goats' response to the incidence of worm infection, more specifically to parasitism in females. The implementation of animal performance records and adjustments in the assembly of the database for the herd was important, especially because it comprises the three traits related to endoparasitism (EPG, BCS and FAMACHA), which started to be collected in all the dams in the herd. The use of irrigated pastures in the dry season of the year ensured that the animals were subjected to parasitic infection pressure throughout the year in the herd, as observed by N. C. S. Silva (2011). Parasitic pressure is a condition required for animals to express resistance to the incidence of worm infection (Bishop, 2012).

Another peculiarity to be considered is the intentional incorporation of females with high EPG counts (potentially sensitive) over four generations in the herd. This initiative was a strategy to expand the genetic variation 
of responses to worm infection in the herd, to meet studies in this area. It proved to be efficient in increasing the number of sensitive animals to the point that measures were required to help control the infection, to keep the more sensitive goats in the herd. To reduce mortality in the peripartum period, all goats were dewormed post-partum, so as not to favor a specific animal.

The evaluated herd had an average of 80 goats in reproduction each year; however, only 101 born in the period from 2009 to 2013 met the imposed restrictions (data from all studied covariates: EPG, BCS, FAMACHA, BS, DAK and BT). Of these animals the minimum and maximum stay lengths, after the first kidding, were 1 and 89 months, respectively. Additionally, 49 (48.51\%) failed, that is, their removal from the herd was due to death, with prevalence of presence of clinical signs associated with worm infection, and 52 (51.49\%) were censored, i.e., they were culled for other reasons (slaughter, research, parturition, etc.), or remained alive in the herd at the end of the considered period. From the standpoint of mortality rate associated with worm infection, the annual average of $12.6 \%$ in the period is high, although no value was found for a similar cause in the literature of goat herds. This high culling frequency associated with worm infection may be a consequence of the strategy used to increase the variability of response to worm infection, which was replacement with the incorporation of potentially sensitive animals (high EPG).
The mean age and standard deviation of the animals that failed were $44 \pm 23$ months, i.e., age varied considerably, in an amplitude that suggests that the influence of worm infection was enhanced by the increase in the goats' age. However, the observed value was greater than the $38 \pm 23$ months shown by the goats that did not fail.

In terms of birth type, 57 (56.44\%) were single births and $44(43.56 \%)$ multiple. Between the seasons, 53 (52.48\%) of the kids were born in the rainy and $48(47.52 \%)$ in the dry season. Dam age at kidding ranged from 12 to 96 months, with $50 \%$ of the mothers of the evaluated goats kidding until 48 months of age, which corresponds to an age range that covers the peak production of goats. To complement this information, Table 2 shows the descriptive statistics associated with each continuous variable in relation to status $(\delta=1$; Failure) and ( $\delta=0$; Censoring).

As regards AFK, among the goats that failed and those which were censored, the mean age and standard deviation for the occurrence of the first kidding were $24 \pm 4$ and $24 \pm 5$ months, respectively, indicating that sensitivity to worm infection was not related to the expression of earliness of the goats regarding parturition. The median value was 23 months for both groups, that is, $50 \%$ of the goats had their first kidding after 23 months of age, which is considered an intermediate age. In addition, for $50 \%$ of the dams, DAK was greater than 48 and 42 months for those that failed and were censored, respectively. 
Table 2

Summary measures ${ }^{\dagger}$ for continuous covariates ${ }^{\ddagger}$ of Anglo-Nubian goats

\begin{tabular}{|c|c|c|c|c|c|c|c|c|c|c|}
\hline \multirow[b]{2}{*}{ Variable } & \multicolumn{5}{|c|}{$\delta=1$ (Failure) } & \multicolumn{5}{|c|}{$\delta=0$ (Censoring) } \\
\hline & $\bar{x}$ & Md & SD & Min & $\operatorname{Max}$ & $\bar{x}$ & Md & SD & Min & $\operatorname{Max}$ \\
\hline AFK (month) & 24 & 23 & 4 & 14 & 33 & 24 & 23 & 5 & 14 & 39 \\
\hline DAK (month) & 47 & 48 & 21 & 12 & 84 & 46 & 42 & 21 & 12 & 96 \\
\hline BCS & 2.11 & 2.10 & 0.49 & 1.00 & 3.30 & 2.12 & 2.00 & 0.54 & 1.00 & 3.50 \\
\hline EPG & 2.669 & 1900 & 2.493 & 300 & 10.800 & 2.369 & 1.600 & 2.397 & 100 & 12.400 \\
\hline BW (kg) & 2.98 & 3.00 & 0.57 & 1.50 & 4.10 & 2.78 & 2.80 & 0.55 & 1.80 & 4.00 \\
\hline
\end{tabular}

${ }^{\dagger} \bar{X}$ : sample mean, Md: median, SD: standard deviation, Min: minimum, Max: maximum

${ }^{\ddagger}$ AFK: age at first kidding (months); DAK: dam age at kidding (months); BCS; body condition score; EPG: eggs per gram of feces; BW: birth weight (kg).

The EPG counts were performed during the gestational and lactating period, when goats tend to have a decline in immunity. As shown in Table 2, the median EPG values of 1,900 or 1,600 indicate greater sensitivity of the goats that failed. According to Batista et al. (2014), the greater sensitivity of goats in the gestational phase to the action of endoparasites is also detected by the degree of anemia of the animals, measured by the
Famacha method, as goats in the peripartum period (gestation-lactation) exhibit higher values, in an indication of a relationship with the EPG behavior. Table 3 shows the total number of goats, failures and censoring of categorical covariates. Of the 101 goats, 86 $(85.15 \%)$ were anemic (FAMACHA $\geq 3$ ), of which 42 (48.84\%) failed (death by worm infection, with prevalence of associated clinical signs).

\section{Table 3}

Number of Anglo-Nubian goats that failed or were censored after the first kidding, per categorical covariate

\begin{tabular}{ccccc|}
\hline Variable & Category & $\mathrm{n}$ & $\delta=1$ (Failure) & $\delta=0$ (Censoring) \\
\hline \multirow{2}{*}{ BS } & Rainy & 42 & $18(42.86 \%)$ & $24(57.14 \%)$ \\
& Dry & 59 & $31(52.54 \%)$ & $28(47.46 \%)$ \\
BT & Single & 57 & $29(50.88 \%)$ & $28(49.12 \%)$ \\
& Multiple & 44 & $20(45.46 \%)$ & $24(54.54 \%)$ \\
FAMACHA & Non-anemic & 15 & $7(46.67 \%)$ & $8(53.33 \%)$ \\
& Anemic & 86 & $42(48.84 \%)$ & $44(51.16 \%)$ \\
\hline
\end{tabular}

*FAMACHA $\geq 3$ (anêmic); FAMACHA <3 (non-anemic). 
Goats born in different seasons of the year can be influenced by different environmental and dietary conditions during the growth phase (Salama et al., 2014), especially in extensive rearing. With respect to $\mathrm{BS}$, as shown in Table 3, the highest percentage of failures $(31 ; 52.54 \%)$ occurred in animals born in the dry season, when the majority of animals were born (59 of 101). In addition, 57 (56.44\%) of the goats were born from single births and, of these, 29 (50.88\%) failed, i.e. they were culled due to death.

Figure 1 (panel (a)) shows the global survival curve as obtained by the KaplanMeier method, with the respective confidence intervals, where the empirical estimate for the mean and median, of the survival times, was 53.72 and 57.0 months, respectively. For instance, the odds of a goat surviving 57 months after the first kidding are $47.86 \%$. In panels (b), (c) and (d) of Figure 1, the survival curves are stratified by categorical covariate. In visual graphic analysis, there appears to be no difference between the BS, BT and FAMACHA categories in relation to the survival curve of the evaluated animals, which was also confirmed by the Log-rank test, adopting a significance level lower than or equal to $10 \%$. The following results were obtained: BS $(p=$ 0.30; $\chi^{2}=1.1$ and $d f=1$ ), BT and FAMACHA ( $p$ $=0.5 ; \chi^{2}=1.1$ and $d f=1$ ), which were evaluated to estimate the survival probabilities of the goats, after the first kidding. (a)

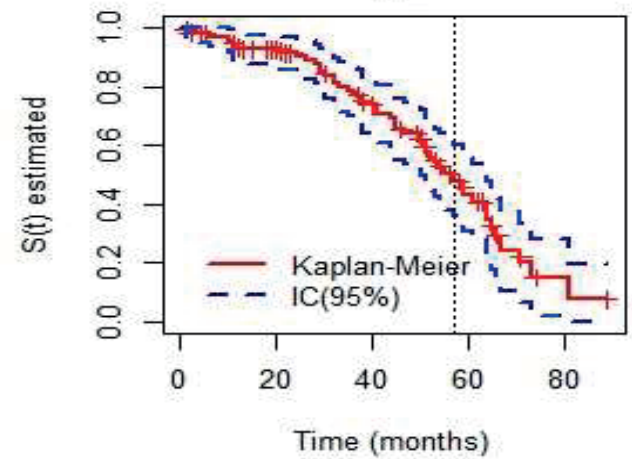

(c)

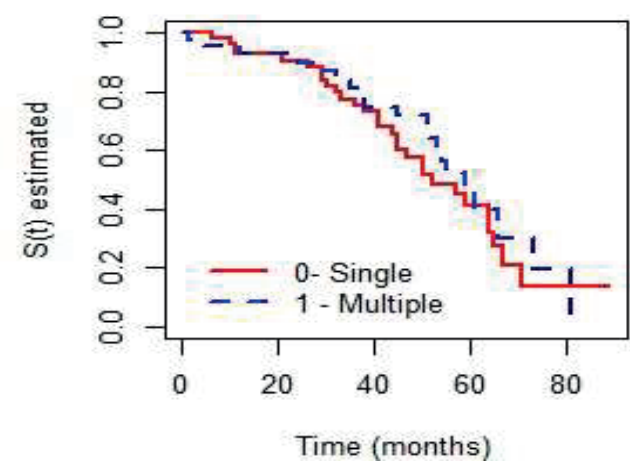

(b)

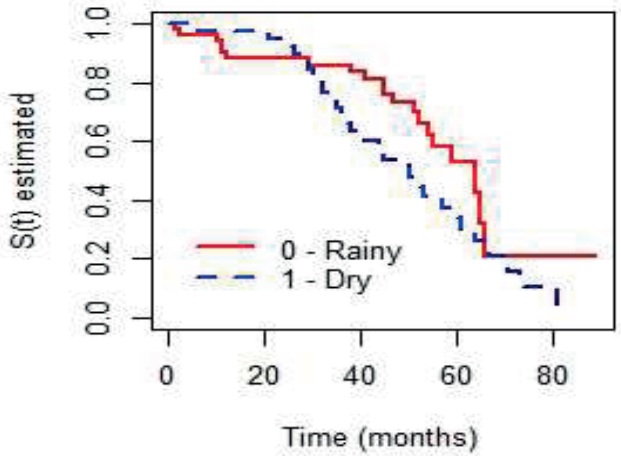

(d)

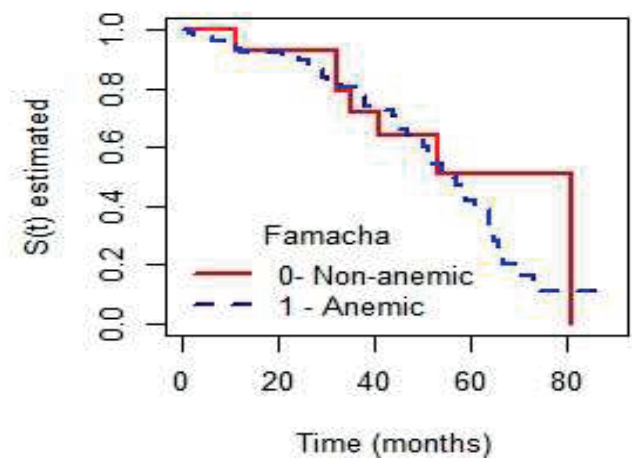

Figure 1. Global survival curve (a) and survival curves as estimated by the Kaplan-Meier method for categorical covariates, namely, birth season (b), birth type (c) and Famacha (d) in Anglo-Nubian goats. 


\section{Fitting of the Cox-Gompertz model}

In the analysis of the influence of covariates on the time the goats stayed in the herd after the first kidding, the CoxGompertz model was fitted (4), starting with a model without a covariate and then including covariates, and using the likelihood ratio test (LRT) as a criterion for comparison. Table 4 shows the results of the parameter estimates, standard error, confidence interval, $p$-value and failure rate ratio (FRR) of the fitted final model. The order of relevance as determined by the covariates was: BCS ( $p=$
0.0105), BW ( $p=0.0105)$ and BS $(p=0.0831)$, respectively, which are factors related to the rearing environment in the region and other peculiarities inherent to the animals.

The hazard (4) and survival (5) functions for the final model are described, respectively, by:

$$
\begin{gathered}
\hat{h}\left(t_{i} \mid x_{i}\right)=0.0012 \exp \left(0.0524 t_{i}\right) g\left(\widehat{\boldsymbol{\beta}}^{\prime} x_{i}\right), \\
\hat{S}\left(t_{i} \mid x_{i}\right)=\left[\exp \left\{-\frac{0.0012}{0.0524}(\exp (0.0524 t)-1)\right\}\right]^{g\left(\widehat{\boldsymbol{\beta}}^{\prime} x_{i}\right)} .
\end{gathered}
$$

where $g\left(\hat{\boldsymbol{\beta}}^{\prime} x_{i}\right)=\exp (0.5205 \times \mathrm{BS}-0.8161 \times$ $B C S+0.7006 \times B W)$.

\section{Table 4}

Maximum likelihood estimates (MLE), standard error (SE), confidence interval ( $95 \% \mathrm{Cl})$, p-value and

\begin{tabular}{|c|c|c|c|c|c|c|}
\hline \multirow{2}{*}{ Parameter } & \multirow{2}{*}{ MLE } & \multirow{2}{*}{ SE } & \multicolumn{2}{|c|}{$\mathrm{Cl}(95 \%)$} & \multirow{2}{*}{$p$-value } & \multirow{2}{*}{ FRR } \\
\hline & & & LL & UL & & \\
\hline V & 0.0524 & 0.0080 & 0.0387 & 0.0639 & $7.18 e-11$ & - \\
\hline$\lambda$ & 0.0012 & 0.0012 & 0.0002 & 0.0085 & 0.3295 & - \\
\hline$\beta_{1(\mathrm{BS})}$ & 0.5206 & 0.3003 & 0.0631 & 0.9259 & 0.0831 & 1.6829 \\
\hline$\beta_{2(B C S)}$ & -0.8161 & 0.3189 & -1.2878 & -0.4845 & 0.0105 & 0.4422 \\
\hline$\beta_{3(\mathrm{BW})}$ & 0.7006 & 0.2739 & 0.2884 & 0.9459 & 0.0105 & 2.0149 \\
\hline
\end{tabular}
failure rate ratio (FRR) for the parameters of the Cox-Gompertz model

The assumption of proportional failure rates must be met so that the Cox-Gompertz proportional hazards model can be considered suitable to the data of this study. Based on the descriptive graphical method, which involves the logarithm of the accumulated failure rate vs. time function for the covariates of BS, BCS and BW (Figure 2), although they are not perfectly parallel at the beginning, in descriptive terms there is no violation of the assumption of proportional failure rates. 
(a)

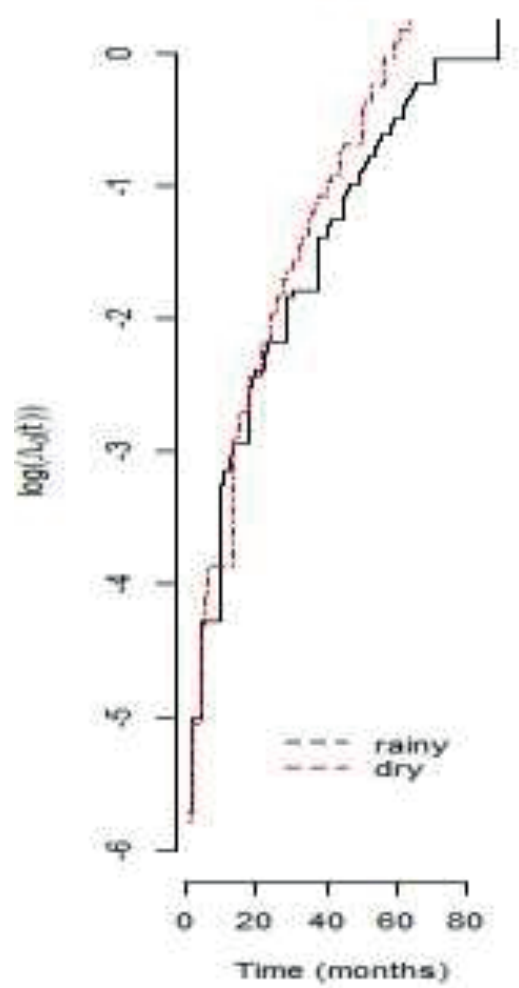

(b)

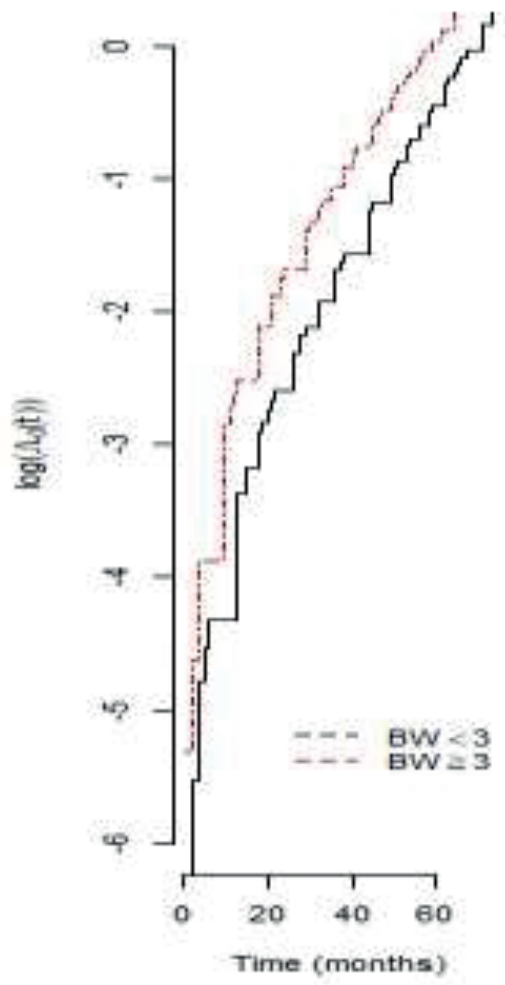

(c)

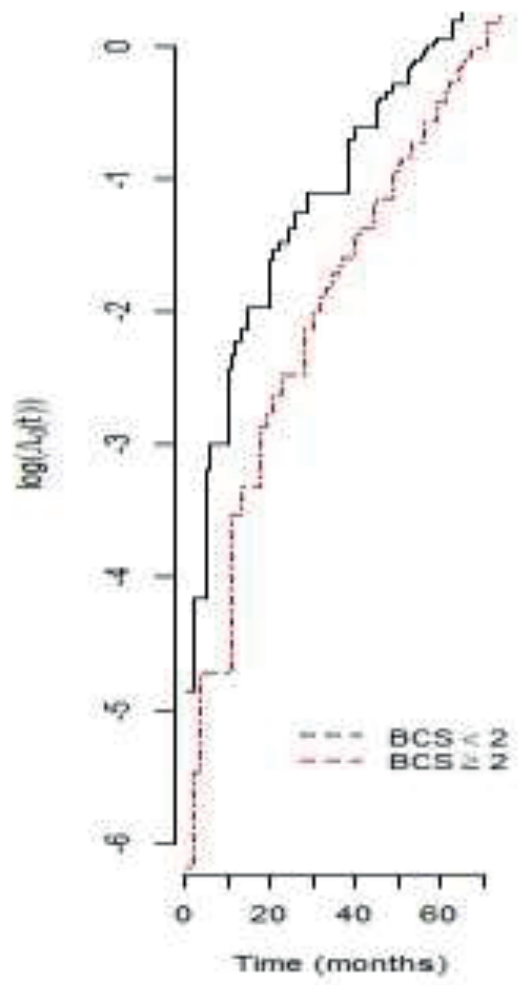

Figure 2. $\log \left(\mathrm{H}_{0 j}(t)\right)$ vs. time for the covariates of birth season (rainy, dry), birth weight (BW) and body condition score (BCS).

In the assessment of goodness of fit of the model, the graphs of the CoxSnell, Martingale and Deviance residuals are illustrated in Figure 3. The survival curves for the Cox-Snell residuals as obtained by the Kaplan-Meier method and the standard exponential model presented (panels (a) and (b)) indicate global goodness of fit of the CoxGompertz parametric model. The Martingale (panel (c)) and Deviance (panel (d)) residuals do not suggest the existence of points that can be considered atypical (outliers). 
(a)

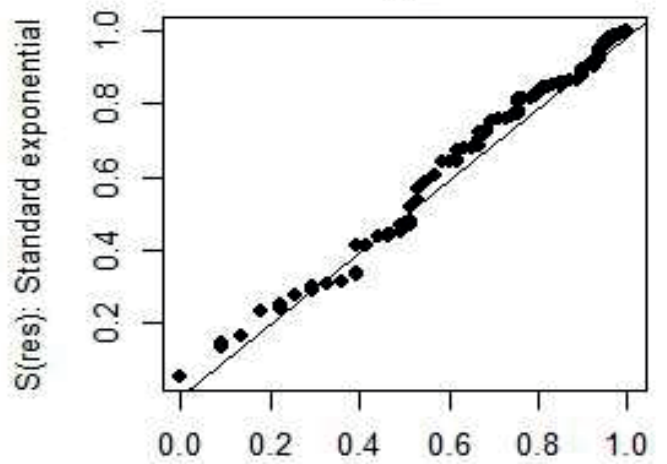

S(res): Kaplan-Meier

(c)

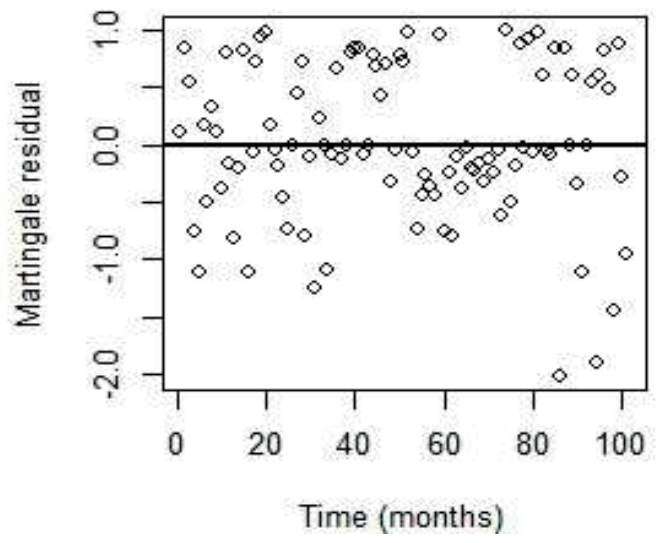

(b)

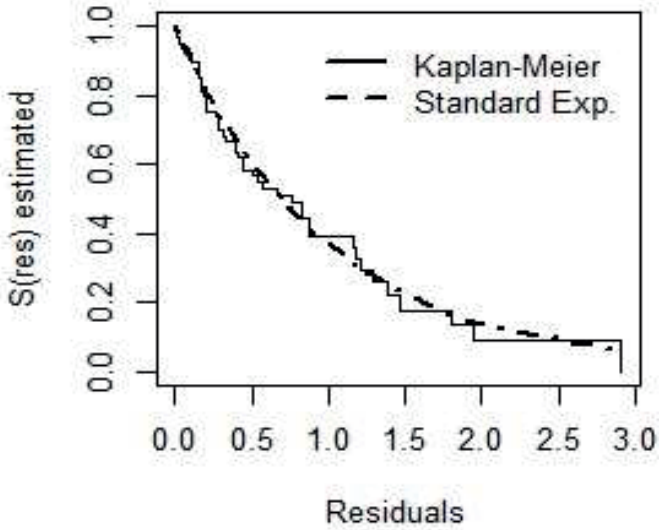

(d)

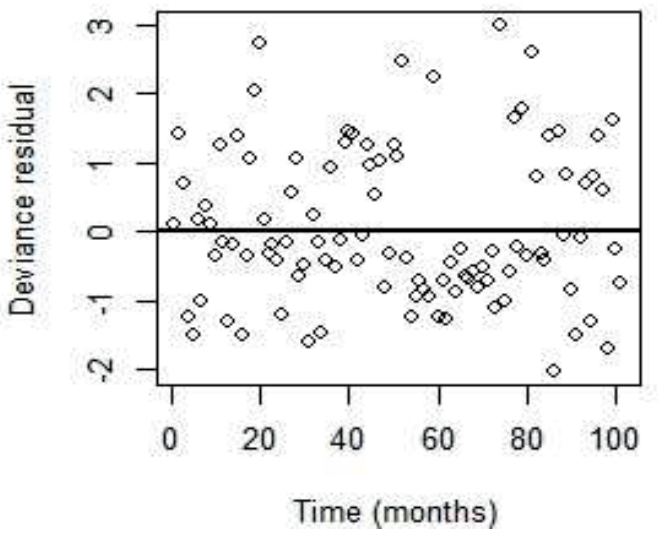

Figure 3. Cox-Snell (a and b), Martingale (c) and Deviance (d) residuals from the Cox-Gompertz model.

For this herd, in which high-EPG females were incorporated intentionally to increase the variation of the animals' response to worm infection, the effects of EPG and FAMACHA two important traits for identification of animals resistant or susceptible to the infection (Snyman \& Fisher, 2019)—were found not to be relevant when considered as covariates for the time the goat stayed in the herd.

The use of a breeding season in the two semesters of the year resulted in very close numbers of goats born in both seasons (dry and rainy). Table 4 shows that the failure rate of goats born in the dry season was 1.68 times higher than that of goats born in the rainy season, with a $68.3 \%$ higher risk of failure. In this case, a high incidence of worm infection can be an aggravating factor for births in the rainy season, whereas lower pasture quality can be an important aggravating factor for births in the dry season. Because of these factors, the recommendation is that reproductive management be planned so that kidding takes place in periods more favorable to the maintenance of dam and offspring (Maylinda, Sarah, \& Busono, 2018). 
The increase in nutritional demand leads to a greater forage intake, and if grazing takes place in areas contaminated by endoparasites, there will also be a greater intake of larvae that can cause intense parasitic infections in the animal. In this case, a seemingly consistent explanation for the lower risk of failure in the rainy-season kiddings was that the deworming performed in the first week after the birth of each goat in the rainy season appears to be more effective in protecting the more sensitive animals, when the parasitic incidence was higher, relative to the application that occurred in the dry season.

As for the significance of the effect of factors inherent to the animal, the failure rate for BCS was 0.442 , indicating that there is a decrease in risk of failure (death, with clinical signs of worm infection) among the goats that manage to maintain a good BCS. Increases in EPG tend to be associated with a higher degree of anemia as determined by the Famacha method, and both are related to a reduction in BCS (Batista et al., 2014). Thus, the maintenance of BCS showed to be a robust indicator of the longer stay of the goats in the herd, that is, goats that showed better body condition in the gestation-lactation period tended to stay longer in the herd.

The influence of the BCS on the longer stay of the goats in the herd can probably be attributed to the resilience or resistance to worm infection shown by some animals, which managed to offset the decline in common immunity in the peripartum period, which occurred in the presence of nematodes as indicated by the EPG count. However, the prevalence of gastrointestinal parasites and the severity of infection depend on factors such as ecological diversity, climatic conditions, mode of use of medications, age, health and nutritional status of the animals (Charlier, Voort, Kenyon, Skuce, \& Vercruysse, 2014).

The failure rate for goat weight at birth considered as a covariate was 2.014 , that is, goats that were born heavier had a $101.4 \%$ risk of failure (death). As the weights in the life stages of a goat tend to be correlated, its adult weight and the weight of the offspring it produced throughout its life, available in the database, but not used in this study, can be covariates of great potential for research of this nature, which warrant investigation.

Animals heavier at birth also tend to be heavier at maturity, implying a greater maintenance requirement of the dam-kid pair. Thus, larger goats may suffer a more pronounced effect of the limited feed supply in the dry season of the year, in addition to exposing themselves to the risk of immunosuppression in the rainy season, due to the ingestion of a greater amount of endoparasite larvae via grazing. In this condition, larger animals would be less suitable for extensive management, in which pasture is the basis to supply the nutritional demand. Some factors evaluated in model (4) were not significant $(p>0.10)$. For instance, with regard to AFK, earliness at kidding was not a decisive factor for the longer or shorter stay of the goat in the herd. In terms of BT, single-birth animals tend to grow larger because they have more milk available from the mother. Larger animals, in turn, tend to first kid later in the same herd, which can lead to the association of these two effects, to the point that they are not detected as significant covariates for the stay of the goat in the herd.

The number of goats born from single births exceeded that of twin births, and 
because, in general, males can also be born in twin births, we may consider that BT is interfering little in the number of dams that are incorporated into the herd. The influence of a mother on the development of its offspring is linear in the growth phase, stabilizes at maturity and then decreases as the mother gets older (Gowane, Chopra, Prakash, \& Prince, 2014). In this study, the effect of dam age at kidding was not significant for the longer or shorter stay of the goats in the herd. Therefore, the longevity of the goats was not related to dam age.

The increase in EPG count is inversely related to the animal's body condition and directly related to a decrease in immunity, an increase in number of eggs eliminated in the feces and spread of the parasite (Costa et al., 2011). The Famacha method is recommended for endoparasitic follow-up due to its high correlation with blood parameters and its practicality to assist in the diagnosis of parasitic infection based on the EPG count (Cornelius, Jacobson, \& Besier, 2014). These are the three most used traits for indicating the animals' response to worm infection, but EPG was not shown to be important as a covariate for the stay of the goats in the herd. The incorporation of animals that showed a high EPG count may have increased the number of sensitive animals in the herd, which behaved with resilience after being dewormed after kidding. The non-significance of the EPG covariate may also be influenced by acquired immunity, which tends to increase with age and may interfere with the ability to respond to parasitism. However, from a practical point of view, it may indicate that it was important to deworm the goats after giving birth. In this study, this was considered a protection measure for those most sensitive to the worm infection, since immunodepression in the peripartum period can make this phase a weak point for the dam, especially if they are very sensitive to parasitic infection, as in those found in the experimental herd used in this study.

A comparative study of the CoxGompertz proportional hazards model with the Cox-Weibull and Cox-Log-normal models was undertaken. Table 5 shows the maximum likelihood estimates for the parameters of the proposed models. The selection of models by the AIC and BIC criteria revealed that the Cox-Gompertz model is the most suitable, as it shows the lowest AIC and BIC values, which indicates that this model has a better goodness of fit to the estimated survival times. Figure 4 illustrates the survival function as estimated by the Kaplan-Meier method with the survival curves as estimated by each adjusted model. As clearly depicted in the graphs of Figure 4, the Gompertz model is the one that best fits the Kaplan-Meier curves. 
Table 5

Maximum likelihood estimates (MLE) and standard error (SE) of parameters of the Cox proportional hazards model with baseline hazard functions: Gompertz, Weibull and log-Normal

\begin{tabular}{ccccccc} 
& \multicolumn{9}{c}{ Model } \\
\cline { 2 - 7 } Parameter & \multicolumn{2}{c}{ Cox-Gompertz } & \multicolumn{2}{c}{ Cox-Weibull } & \multicolumn{2}{c}{ Cox log-Normal } \\
\cline { 2 - 7 }$\mu$ & MLE & SE & MLE & SE & MLE & SE \\
$\sigma$ & & - & - & - & 6.1322 & 0.7380 \\
$Y$ & & - & - & - & 1.3225 & 0.1809 \\
$\lambda$ & 0.0524 & 0.0080 & 2.1764 & 0.2619 & - & - \\
$\beta_{1(\mathrm{BS})}$ & 0.0012 & 0.0018 & 88.8121 & 40.4906 & - & - \\
$\beta_{2(\mathrm{BCS})}$ & 0.5206 & 0.3002 & 0.4569 & 0.2996 & 0.5189 & 0.3085 \\
$\beta_{3(\mathrm{BW})}$ & -0.8161 & 0.3003 & -0.6161 & 0.3092 & -0.2078 & 0.2785 \\
$\log$-likelihood & 0.7006 & 0.2739 & 0.6191 & 0.2647 & 0.9097 & 0.2454 \\
AIC & 480.2392 & 493.5072 & 511.4361 \\
BIC & 490.2392 & 503.5072 & 521.4361
\end{tabular}

The methods presented in this study, through survival analysis, can contribute to breeding programs for animals of production interest in terms of performance (production, reproduction) and health. The methodology can be applied to investigate the longevity of breeding stock, associated with points of weaknesses of genetic or environmental nature (unobservable factors that negatively affect reproductive and productive efficiency). In addition, it can be employed to model the time the animal takes to reach a certain pre-defined weight or daily weight gain in a production system focused on animals for slaughter or even in the selection of males and/or females of superior performance. 


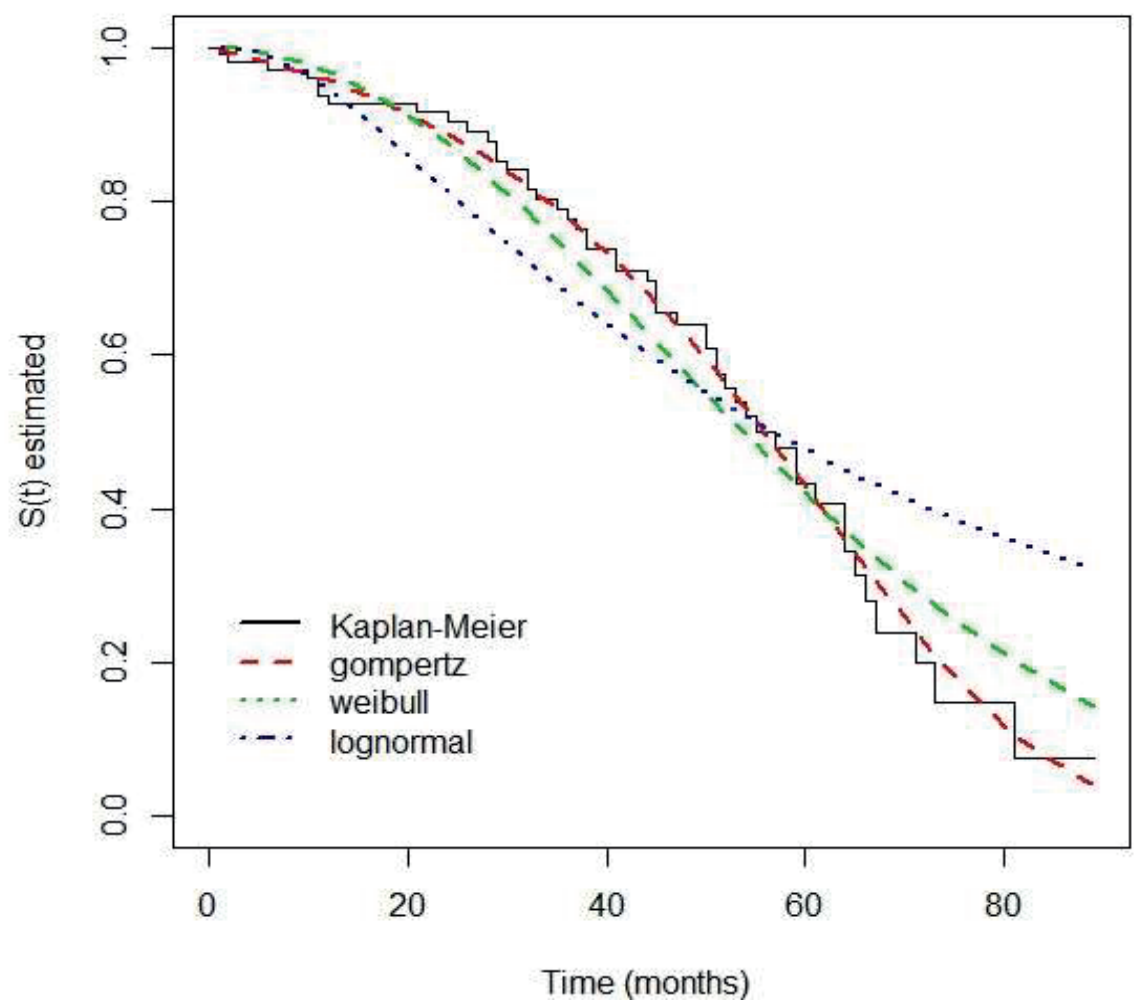

Figure 4. Survival curves as estimated by the fitted models vs. survival curve as estimated by the Kaplan-Meier method.

\section{Conclusion}

This study shows that survival analysis models can be useful to assess the length of stay of Anglo-Nubian goats in the herd, since physiological factors such as EPG, $\mathrm{BCS}$, FAMACHA demonstrated the greater tolerance of these animals, which, even when parasitized, managed to maintain good levels of productivity, resulting in a longer stay in the herd. These, combined with environmental factors such as BS, indicated that the climatic differences and the variation in feed availability in the different seasons of the year may be limiting factors for the stay of animals in a commercial herd.

\section{References}

Akaike, H. (1974). A new look at the statistical model identification. IEEE Transactions on Automatic Control, 19(6), 716-723. doi: 10.1109/TAC.1974.1100705

Batista, J. F., Campelo, J. E. G., Morais, M. F., Silva, P. O., Magalhães, P. C., Barçante, F. P. D. S., \& Mendonça, I. L. (2014). Endoparasitismo gastrintestinal em cabras da raça Anglonubiana. Revista Brasileira de Saúde e Produção Animal, 15(2), 318-326. doi: 10.1590/S1519-9940 2014000200016

Bishop, S. C. (2012). A consideration of resistance and tolerance for ruminant nematode infections. Frontiers in 
Genetics, 3(1), 168. doi: 10.3389/fgene. 2012.00168

Castañeda-Bustos, V. J., Montaldo, H. H., Valencia-Posadas, M., Shepard, L., PérezElizalde, S., Hernández-Mendo, O., \& Torres-Hernández, G. (2017). Linear and nonlinear genetic relationships between type traits and productive life in US dairy goats. Journal of Dairy Science, 100(2), 1232-1245. doi: 10.3168/ jds.2016-11313

Charlier, J., Voort, M., Kenyon, F., Skuce, P., \& Vercruysse, J. (2014). Chasing helminths and their economic impact on farmed ruminants. Trends in Parasitology, 30(7), 361-367. doi: 10.1016/jpt.2014.04.009

Colosimo, E. A., \& Giolo, S. R. (2006). Análise de sobrevivência aplicada. São Paulo, SP: Editora Blucher.

Conrado, V. D. C., Arandas, J. K. G., \& Ribeiro, M. N. (2015). Regression models to predict the weight of Caninde goat breed through morphometric measures. Archivos de Zootecnia, 64(247), 277-280. doi: 10.21 071/az.v64i247.400

Cornelius, M. P., Jacobson, C., \& Besier, R. B. (2014). Body condition score as a selection tool for targeted selective treatment-based nematode control strategies in Merino ewes. Veterinary Parasitology, 206(3-4), 173-181. doi: 10. 1016/j.vetpar.2014.10

Costa, V. M. M., Simões, S. V. D., \& Riet-Correa, F. (2011). Controle das parasitoses gastrintestinais em ovinos e caprinos na região semiárida do Nordeste do Brasil. Pesquisa Veterinária Brasileira, 31(1), 65-71. doi: 10.1590/S0100-736X 2011000100010.
Cox, D. R. (1972). Regression models and lifetables. Journal of the Royal Statistical Society: Series B (Methodological), 34(2), 187-202. doi: 10.1111/j.2517-6161.1972. tb00899.x

Cox, D. R., \& Snell, E. J. (1968). A general definition of residuals. Journal of the Royal Statistical Society: Series B (Methodological), 30(2), 248-265. doi: 10. 1111/j.2517-6161.1968.tb00724.x

Dey, S., Moala, F.A., \& Kumar, D. (2018).Statistical properties and different methods of estimation of Gompertz distribution with application. Journal of Statistics and Management Systems, 21(5), 839-876. doi: 10.1080/09720510.2018.1450197

Ferreira, T.A., Martins, P.G., Gouveia, G.C., Abreu, L. R., Gouveia, A. M., Facó, O.,... Pereira, I. G. (2020). Proportional hazard models associated with the survival of dairy goats reared in a tropical environment. Small Ruminant Research, 184, 106063. doi: 10. 1016/j.smallrumres.2020.106063

Finch, C. E., \& Pike, M. C. (1996). Maximum life span predictions from the Gompertz mortality model. The Journals of Gerontology Series A: Biological Sciences and Medical Sciences, 51(3), B183-B194. doi: 10.1093/gerona/51a.3.b183

Gowane, G. R., Chopra, A., Prakash, V., \& Prince, L. L. L. (2014). The role of maternal effects in sheep breeding: a review. Indian Journal of Small Ruminants, 20(1), 1-11.

Hayward, A. D., Nussey, D. H., Wilson, A. J., Berenos, C., Pilkington, J. G., Watt, K. A.,... Graham, A. L. (2014). Natural selection on individual variation in tolerance of gastrointestinal nematode infection. PLoS Biology, 12(7), e1001917. doi: 10.1371/ journal.pbio.1001917 
Kaplan, E. L., \& Meier, P. (1958). Nonparametric estimation from incomplete observations. Journal of the American Statistical Association, 53(282), 457-481. doi: 10. 2307/2281868

Kirkwood, T. B. (2015). Deciphering death: a commentary on Gompertz (1825) "On the nature of the function expressive of the law of human mortality, and on a new mode of determining the value of life contingencies". Philosophical Transactions of the Royal Society of London. Series B, Biological Sciences, 370(1666), 20140379. doi: 10.1098/rstb. 2014.0379

Lawless, J. F. (2011). Statistical models and methods for lifetime data. Hoboken, NJ: Wiley.

Lima, C. M., Tomazella, V. L., Campelo, J. E., Anastácio, J. L. A., Fo., Barioni, W., Jr., \& Sousa, S. C., Jr. (2021). Gamma-Gompertz shared frailty model for analysis of the time of stay in an Anglo-Nubian goat herd. Small Ruminant Research, 199, 106368. doi: 10.1016/j.smallrumres.2021.106368

Machado, R., Corrêa, R. F., Barbosa, R. T., \& Bergamaschi, M. A. C. M. (2008). Escore da condição corporal e sua aplicação no manejo reprodutivo de ruminantes. São Carlos, SP: EMBRAPA.

Mantel, N., \& Haenszel, W. (1959). Statistical aspects of the analysis of data from retrospective studies of disease. Journal of the National Cancer Institute, 22(4), 719-748. doi: 10.1093/jnci/22.4.719

Maylinda, S., Sarah, O. L., \& Busono, W. (2018). Role of seasons on the production and reproduction performance of kacang goats (Kambing kacang) in North Middle Timor Regency. Indian Journal of Animal
Research, 52(8), 1227-1231. doi: 10.18 805/ijar.B-668

Molento, M. B., Tasca, C., Gallo, A., Ferreira, M., Bononi, R., \& Stecca, E. (2004). Método Famacha como parâmetro clínico individual de infecção por Haemonchus contortus em pequenos ruminantes. Ciência Rural, 34(4), 1139-1145. doi: 10. 1590/S0103-84782004000400027

Molento, M. B., Veríssimo, C. J., Amarante, A. T., van Wyk, J. A., Chagas, A. C. S., Araújo, J. V., \& Borges, F. A. (2013). Alternativas para o controle de nematoides gastrintestinais de pequenos ruminantes. Arquivo do Instituto Biológico, 80(2), 253-263. doi: 10.1590/S1808-16572013000200018

Moore, D. F. (2016). Applied survival analysis using R. New York, NY: Springer.

Nikulin, M. S., Balakrishnan, N., Mesbah, M., \& Limnios, N. (Eds.), (2013). Parametric and semiparametric models with applications to reliability, survival analysis, and quality of life. Boston: Springer Science \& Business Media.

Queiroz, S. A. (2012). Introdução ao melhoramento genético de bovinos de corte. Guaíba: Agrolivros.

Quintas, H., \& Cardoso, L. (2012). Vermes parasitas digestivos de ovinos e caprinos. Guia sanitário para criadores de pequenos ruminantes. In A. Mendonça (Ed.), Guia sanitário para criadores de pequenos ruminantes (pp. 155-164). Bragança, Portugal: Instituto Politécnico de Bragança.

R Core Team (2013). R: A Language and environment for statistical computing. Vienna, Austria: R Foundation for Statistical Computing. 
Salama, A. A. K., Caja, G., Hamzaoui, S., Badaoui, B., Castro-Costa, A., Façanha, D. A. E.,... Bozzi, R. (2014). Different levels of response to heat stress in dairy goats. Small Ruminant Research, 121(1), 73-79. doi: 10.1016/j.smallrumres.2013.11.021

Schwarz, G. (1978). Estimating the dimension of a model. The Annals of Statistics, 6(2), 461-464. doi: 10.12 14/aos/1176344136

Silva, M. G. C. M., Diniz, C. R., \& Rosado, A. C. (2015). Criação racional de caprinos. Lavras, MG: UFLA.

Silva, N. C. S. (2011). Efeitos ambientais que interferem no endoparasitismo em matrizes da raça Anglonubiana em Teresina - Piauí. 2010. Dissertação de mestrado, Pós-Graduação em Ciência Animal, Universidade Federal do Piauí, Teresina, PI, Brasil.

Silveira, F. A., Ferreira, O. G. L., Coelho, R. T., Brondani, W. C., Costa, O. A. D., \& Esteves, R. M. G. (2013). Influência da idade na resistência à verminose de borregas cruza Lacaune. Anais da Jornada Acadêmica Integrada, Universidade Federal de Santa Maria, Santa Maria, RS, Brasil, 28. Recuperado de https://www. researchgate.net/publication/280114494
Snyman, M. A., \& Fisher, A. D. (2019). Genetic parameters for traits associated with resistance to Haemonchus contortus in a South African Dohne Merino sheep flock. Small Ruminant Research, 76-88(176), 76-88. doi: 10.1016/j.smallrumres.2019. 01.004

Stotzer, E. S., Lopes, L. B., Eckstein, C., Moraes, M. C. M. M., Rodrigues, D. S., \& Bastianetto, E. (2014). Impacto econômico das doenças parasitárias na pecuária. Revista Brasileira de Higiene e Sanidade Animal, 8(3), 198-221. doi: 10.5935/1981-2965. 20140128

Torres, T. S. (2019). Métodos tradicionais e genômicos aplicados ao melhoramento genético de ovinos para resistência a verminose. Tese de doutorado, Pós-graduação em Ciência Animal, Universidade Federal do Piauí, Teresina, PI, Brasil. 
